\title{
GAYA KEPEMIMPINAN TRANSFORMASIONAL DAN KONFLIK KERJA-KELUARGA KARYAWAN INDUSTRI MANUFAKTUR
}

\author{
Krismasita Surya Putri, Artiawati, dan Ni Putu Adelia Kesumaningsari \\ Fakultas Psikologi, Universitas Surabaya \\ Jalan Raya Rungkut, Kali Rungkut, Kecamatan Rungkut, Surabaya, Jawa Timur \\ E-mail: skrismasita10@gmail.com
}

\begin{abstract}
ABSTRAK
Penelitian ini bertujuan untuk menguji hubungan antara gaya kepemimpinan transformasional seorang atasan dengan tingkat konflik kerja-keluarga karyawannya. Responden penelitian berasal dari karyawan perusahaan industri manufaktur sepeda dengan total responden sebanyak 117 orang yang dipilih dengan teknik pemilihan probability sampling-simple random sampling. Data yang terkumpul dalam penelitian ini didapatkan dengan menyebarkan angket penelitian yang berisi skala kepemimpinan transformasional dan konflik kerja-keluarga yang selanjutnya dianalisis dengan menggunakan teknik analisis korelasi. Hasil analisis data korelasi menunjukkan bahwa tidak terdapat hubungan negatif yang signfikan antara gaya kepemimpinan transformasional atasan dan konflik kerja-keluarga karyawan. Namun, pengolahan data lebih lanjut menunjukkan bahwa terdapat hubungan antara 5 dari 7 aspek gaya kepemimpinan transformasional yakni vision, staff development, empowerment, innovative thinking, dan lead by example dengan salah satu aspek dari konflik kerja-keluarga yakni family interference work-strain. Penelitian ini juga menghasilkan temuan lain yakni adanya asosiasi antara jenis kelamin atasan dengan tingkat konflik kerja-keluarga karyawan, yakni atasan berjenis kelamin perempuan cenderung lebih transformasional dibandingkan atasan berjenis kelamin laki-laki. Hasil yang demikian mengindikasikan bahwa karyawan yang dipimpin oleh seorang pemimpin yang transformasional akan merasa memiliki panutan yang dapat memberikannya contoh dalam mengatasi konflik peran dalam lingkup keluarga dan pekerjaannya. Dengan demikian, karyawan dapat mengadaptasi pola keseimbangan kerja-keluarga dari atasannya dan mempraktikkannya dalam kehidupan rumah tangganya sehingga tekanan dari peran yang dimiliki dalam lingkup keluarga tidak sampai mengganggu perannya di lingkungan kerja.
\end{abstract}

Kata kunci: konflik kerja-keluarga; gaya kepemimpinan transformasional; karyawan industri manufaktur

\section{TRANSFORMATIONAL LEADERSHIP AND WORK-FAMILY CONFLICT AMONG MANUFACTURING INDUSTRY EMPLOYEES}

\begin{abstract}
The main purpose of this research was to examine whether there is a significant correlation between supervisor's transformational leadership with employee's work-family conflict. The respondents of this research were taken from bicycle manufacturing company's employees with a total of 117 people who were selected using probability sampling-simple random sampling technique. Data collection was obtained by distributing research questionnaire, i.e. the scale of transformational leadership and work-family conflict and analyzed with correlation analysis techniques. Result of this study indicates that there is no significant correlation between supervisor's transformational leadership and employee's work-family conflict. However, there are correlation between 5 of 7 aspects of transformational leadership, that is vision, staff development, empowerment, innovative thinking, and lead by example, with an aspect of work-family conflict, that is family interference work-strain. This research also found that there was an association between gender of the leader and the level of employee's work-family conflict, that is female leader tend to be more transformational than male leader. The result indicates that employees led by a transformational leader will feel that they have a role model who can give them examples in overcoming any conflict that occurs in the family and work interface. Thus, the employees finally also adapt the work-family balance design that they learned from their supervisor and practice it in their family's life so the strain from role that they have in their family's life doesn't affect their role in work's life.
\end{abstract}

Keywords: work-family conflict; transformational leadership; manufacturing industry employee 


\section{PENDAHULUAN}

Hidup seorang individu tidak bisa terlepas dari peran-peran sosial yang melekat pada dirinya dari lingkungan tempatnya bernaung. Seorang individu yang telah memasuki tahapan dewasa paling tidak mengemban minimal dua macam peran dalam hidupnya, yakni perannya di dalam keluarga dan pekerjaan. Hal tersebut dikarenakan dua lingkup terpenting bagi seorang individu dewasa adalah keluarga dan pekerjaan (Magnini, 2009). Realita menunjukkan bahwa terjadi peningkatan fenomena jumlah penduduk yang bekerja. Badan Pusat Statistik pada tahun 2019 memaparkan bahwa jumlah penduduk yang bekerja per Februari 2019 mengalami peningkatan sebesar 4,32\% jika dibandingkan dengan keadaan pada Agustus 2018 (BPS-RI, 2019). Kondisi tersebut sejalan dengan adanya peningkatan jumlah perempuan yang bekerja yakni sebesar 7,9\%. Data Sakernas 2015 (KEMENPPA, 2016) lebih lanjut mengungkapkan bahwa hampir setengah perempuan yang berstatus menikah, yakni tepatnya sebesar $49,26 \%$, juga memutuskan untuk bekerja. Fakta lainnya memaparkan bahwa jumlah perempuan yang menjadi kepala rumah tangga karena cerai mati atau hidup serta memiliki anak berusia 5-18 tahun dengan jumlah anak sebanyak 1 hingga lebih dari 4 anak menyentuh persentase di atas $80 \%$ (KEMENPPA, 2016). Adanya fenomena peningkatan jumlah pasangan bekerja atau yang disebut sebagai dual earner couple (Elloy \& Smith, 2003) serta single parent (Reimann et al., 2019) dapat mengarah terhadap terjadinya suatu konflik yakni konflik kerja-keluarga.

Konflik kerja-keluarga menjadi topik serius yang perlu dicermati dan mendapat perhatian dari perusahaan atau organisasi mengingat ternyata peningkatan jumlah kematian individu dewasa saat ini banyak berkaitan dengan konflik yang terjadi di tempat kerja dan kepentingan keluarga (Spross, 2018). Seorang profesor dari sekolah bisnis di Stanford, yakni Jeffrey Pfeffer, memaparkan dalam penelitiannya bahwa kondisi tempat kerja yang menyebabkan jumlah kematian meningkat tidak semata-mata karena masalah polusi berbahaya yang terdapat dalam lingkungan kerja tersebut, tetapi justru berkaitan dengan kecemasan karyawan terhadap pekerjaannya, seperti takut PHK, jam kerja yang panjang, jadwal yang melelahkan, gaji yang minim, tuntutan pekerjaan yang tinggi, dan konflik kerja-keluarga (Goh et al., 2015). Hal tersebut didukung dengan data yang dipaparkan dalam artikel portal USA Today yang ditulis oleh Stephanie Armour pada tahun 2002 mengenai tuntutan karyawan terhadap pekerjaannya yang menyebutkan bahwa sebesar 32\% mengindikasikan bahwa karyawan menginginkan keseimbangan antara kehidupan keluarga dan pekerjaan (Magnini, 2009). Selain itu, konflik kerja-keluarga menjadi fenomena yang perlu diperhatikan akibat dampak negatif yang dihasilkannya. Hasil penelitian memaparkan bahwa konflik kerja-keluarga dapat membuat seorang karyawan mengalami stres, burnout, dan menurunkan kepuasan kerja, komitmen kerja, serta citizenship (Amstad et al., 2011). Selain itu, seorang karyawan yang terindikasi mengalami konflik kerja-keluarga juga akan memiliki pemikiran yang buruk terhadap kepuasan dan pengembangan karirnya (Liao et al., 2019). Selain dampak negatif yang telah disebutkan sebelumnya, karyawan yang terpapar dengan konflik kerja-keluarga ternyata juga memiliki kecenderungan yang besar untuk mengalami stress kerja yang kemudian berdampak pada perilaku penurunan kualitas kerja hingga kecenderungan mengalami turnover (Amiruddin et al., 2019; Pan \& Yeh, 2019). Turnover merupakan suatu bentuk tendensi yang secara sadar dirasakan oleh karyawan untuk sengaja meninggalkan perusahaan (Li et al., 2019; Meyer \& Tett, 1993). Selain efek-efek negatif yang telah dipaparkan sebelumnya, konflik kerja-keluarga juga membawa dampak negatif terhadap performa kerja, lateness, absenteeism, dan presenteeism (Magnini, 2009).

Konflik kerja-keluarga merupakan sebuah kondisi konflik yang terjadi akibat adanya tumpang tindih dari peran yang dimiliki oleh seorang individu (Greenhaus \& Beutell, 1985). Konflik kerja-keluarga bersifat multidimensi yang terdiri atas time-based conflict, strain-based conflict, dan behavior-based conflict. Setiap dimensi tersebut memiliki hubungan yang bersifat bidirectional dan interdependensi, yakni work interference family (WIF) dan family interference work (FIW). Kendati demikian, penelitian ini hanya menggunakan dimensi WIF dan FIW time dan strain based conflict karena dimensi behavior-based conflict belum dapat secara spesifik menjabarkan perilaku-perilaku apa saja yang perlu diamati dari setiap peran yang dimiliki oleh individu sehingga masih belum ditemukan penelitian yang secara jelas dan empiris meneliti dan menilai prevalensi dari aspek ini secara konkret (Greenhaus \& Beutell, 1985).

Banyak penelitian yang sudah dilakukan guna menemukan penyebab-penyebab yang sekiranya berpengaruh terhadap konflik kerja-keluarga. Salah satu penyebab yang berperan terhadap tinggi rendahnya tingkat konflik kerjakeluarga yakni berasal dari orang-orang yang dengan signifikan berada di sekitar individu tersebut, misal atasan, pasangan, dan/atau rekan kerja (Kailasapathy \& Jayakody, 2018). Peran seorang atasan sendiri juga memegang kunci penting untuk dapat memberikan pengaruh terhadap para karyawannya, dengan kata lain, pemimpin menjadi pihak yang berpotensi untuk memberikan pengaruh terhadap performa kerja karyawannya (Hammond et al., 2015; Perry \& Penney, 2010; Arnold et al., 2007). Arnold et al. (2007; Hammond et al., 2015) juga menyebutkan bahwa pemimpin menjadi faktor yang penting dalam menentukan kesejahteraan pegawainya.

Temuan mengenai hubungan yang signifikan antara peran gaya kepemimpinan transformasional dan konflik kerja-keluarga juga secara jelas dipaparkan dalam penelitian milik Hammond et al. (2015) dan Gillet et al. (2016). 
Gaya kepemimpinan transformasional berhubungan secara signifikan dengan konflik kerja-keluarga namun juga dimediasi oleh otonomi, positive affect, serta dukungan atasan (Hammond et al., 2015). Selain itu, gaya kepemimpinan transformasional juga berhubungan signifikan dengan konflik kerja-keluarga yang menjadi mediator antara gaya kepemimpinan transformasional dengan komitmen organisasi (Gillet et al., 2016). Dengan demikian, dapat disimpulkan bahwa seorang pimpinanmemiliki peran penting yang dapat secara langsung memengaruhi konflik kerjakeluarga karyawannya.

Peran atasan sendiri tidak dapat dipisahkan dari gaya kepemimpinan yang dimilikinya. Konsep gaya kepemimpinan awalnya dikemukakan oleh Burns pada tahun 1978 dengan membaginya menjadi gaya kepemimpinan transaksional dan transformasional (Bass, 1997). Pemimpin bergaya transaksional merupakan tipe pemimpin yang task-oriented, sementara pemimpin bergaya transformasional merupakan tipe pemimpin yang person-oriented. Gaya kepemimpinan transformasional bersifat multidimensi yang terdiri atas dimensi inspirational motivation, individualized consideration, idealized influence, dan intellectual stimulation (Bass \& Avolio, 1990). Kendati demikian, penelitian ini menggunakan dimensi yang dikembangkan oleh Carless et al. yang terdiri dari vision, staff development, supportive leadership, empowerment, innovative thinking, lead by example, dan charisma (Carless et al., 2000).

Berdasarkan uraian di atas, maka pada penelitian ini gaya kepemimpinan transformasional akan dilihat hubungannya ke masing-masing dimensi konflik kerja-keluarga yakni work interference family-strain, work interference family-time, family interference work-strain, family interference work-time, dan akan menyasar pada karyawan industri manufaktur. Pemilihan industri manufaktur menjadi sasaran partisipan penelitian karena karyawan manufaktur memiliki tingkat stres yang tinggi. Peningkatan stres secara signifikan terjadi pada karyawan manufaktur saat mereka dihadapkan pada deadline dan memiliki tanggung jawab yang berlebihan (work overload) (Yeow et al., 2012). Selain itu, kondisi lingkungan kerja juga dapat berkontribusi dalam meningkatkan stres (work environment stress) dan tekanan psikologis (psychological strain) para karyawannya (LaRocco et al., 1980; Yeow et al., 2012). Stres akibat lingkungan kerja sendiri dapat berasal dari berbagai penyebab seperti polusi udara akibat mesin-mesin pabrik, debu, bau kimia, dan lain sebagainya yang dapat memengaruhi konsentrasi karyawan dalam menyelesaikan tanggung jawab pekerjaannya (Sherman, 1999; Yeow et al., 2012). Adanya peningkatan stres yang dialami oleh karyawan ternyata berkorelasi positif dengan tingkat konflik kerja-keluarga karyawan. Hal tersebut terbukti dari penelitian yang dilakukan oleh Tziner dan Sharoni yang memaparkan bahwa semakin tinggi stres yang dialami oleh karyawan, semakin tinggi pula tingkat konflik kerja-keluarganya (Tziner \& Sharoni, 2014). Oleh karena adanya pemaparan mengenai stressor yang potensial terjadi pada industri manufaktur untuk mengalami konflik kerjakeluarga serta buruknya dampak dari konflik kerja-keluarga itulah, maka sangat penting untuk meneliti faktor-faktor yang potensial berkaitan dengan konflik kerja-keluarga, salah satunya adalah gaya kepemimpinan transformasional yang teruji berkorelasi signifikan dengan konflik kerja-keluarga sesuai dengan penelitian yang telah dilakukan oleh Hammond et al. (2015) dan Gillet et al. (2016).

\section{METODE}

Penelitian ini merupakan penelitian berjenis kuantitatif dengan teknik pemilihan sampel yaitu probability sampling-simple random sampling yang memiliki total responden sebanyak 117 orang dengan rasio responden berjenis kelamin laki-laki dan perempuan sebanyak 82 berbanding 35 orang. Responden tersebar di rentang usia 19 sampai 55 tahun $(M=31,0172 ; \mathrm{SD}=6,81301)$ dengan mayoritas responden berada di jenjang usia 21-30 tahun $(56,4 \%)$ dan telah bekerja di perusahaan selama mayoritas 3 sampai 5 tahun (44,4\%). Mayoritas responden juga telah berkeluarga dengan rentang usia pernikahan 3 sampai 10 tahun (46,2\%) dan telah memiliki seorang anak (33,3\%). Secara keseluruhan, sebagian besar responden juga merupakan seorang dual earner couple karena mayoritas pasangannya bekerja (53\%) secara full time (36,8\%). Penelitian ini juga mencermati jenis kelamin dari atasan para responden mengingat salah satu variabel yang diteliti dalam penelitian ini adalah variabel gaya kepemimpinan transformasional. Adapun rasio frekuensi antara jenis kelamin atasan para responden yang berjenis laki-laki dan perempuan adalah sebanyak 87 orang berbanding 22 orang. Dengan demikian dapat pula disimpulkan bahwa dalam penelitian ini mayoritas responden memiliki atasan yang berjenis kelamin laki-laki. Lebih jelasnya, data demografi dari partisipan penelitian ini akan dipaparkan pada tabel-tabel berikut ini:

Tabel 1. Distribusi Jenis Kelamin Responden

\begin{tabular}{lccc}
\hline & Jenis Kelamin & Frekuensi & Persentase \\
\hline Laki-laki & 82 & $70,1 \%$ \\
Perempuan & 35 & $29,9 \%$ \\
\hline
\end{tabular}


Tabel 2. Distribusi Usia

\begin{tabular}{lcccc} 
& Rentang Usia & Subjek & Pasangan \\
\% & f & f & \multicolumn{2}{c}{ P } \\
\hline$>50$ & 1 & $0,9 \%$ & 1 & $0,9 \%$ \\
$41-50$ & 10 & $8,5 \%$ & 5 & $4,3 \%$ \\
$31-40$ & 36 & $30,8 \%$ & 32 & $27,4 \%$ \\
$21-30$ & 66 & $56,4 \%$ & 60 & $51,3 \%$ \\
$<21$ & 3 & $2,6 \%$ & 0 & $0 \%$ \\
Abstain & 1 & $0,9 \%$ & 19 & $16,2 \%$ \\
\hline
\end{tabular}

Tabel 3. Distribusi Jabatan

\begin{tabular}{|c|c|c|}
\hline Jabatan & Frekuensi & Persentase \\
\hline Staf admin & 62 & $52,9 \%$ \\
\hline Operator & 13 & $11,1 \%$ \\
\hline Foreman & 6 & $5,1 \%$ \\
\hline Mekanik & 6 & $5,13 \%$ \\
\hline OB & 6 & $5,1 \%$ \\
\hline Driver & 4 & $3,4 \%$ \\
\hline Tenaga Kesehatan & 1 & $0,9 \%$ \\
\hline Asisten Manager & 1 & $0,9 \%$ \\
\hline Abstain & 18 & $15,4 \%$ \\
\hline
\end{tabular}

Tabel 4. Distribusi Jenis Kelamin Atasan

\begin{tabular}{lccc}
\hline & Jenis Kelamin & Frekuensi & Persentase \\
\hline Laki-laki & 87 & $74,4 \%$ \\
Perempuan & 22 & $18,8 \%$ \\
Abstain & 8 & $6,8 \%$ \\
\hline
\end{tabular}

Dalam teknisnya, responden mengisi angket berisi instrumen Global Transformational Leadership milik Carless et al. (2000) yang terdiri atas 7 dimensi dan instrumen Work-Family Conflict milik Carlson et al. yang terdiri atas 4 dimensi (Carlson et al., 2000). Peneliti melakukan modifikasi pada instrumen gaya kepemimpinan transformasional dengan menambahkan masing-masing 2 butir pada tiap dimensi dengan penjabaran 1 butir unfavourable dan 1 butir favourable sehingga total butir keseluruhan yakni sebanyak 21 butir. Validitas instrumen modifikasi ini diuji secara forward and back translation oleh subject matter expert dan telah melalui proses uji coba kepada 30 orang karyawan perusahaan manufaktur bumbu dapur instan. Hasil proses uji coba menunjukkan bahwa instrumen ini merupakan instrumen yang reliabel karena alpha cronbach dari instrumen ini sebesar 0,934 dengan rentang koefisien korelasi antar itemnya sebesar 0,324-0,818 dan tanpa ada satupun butir yang dibuang.

Sementara itu, variabel konflik kerja-keluarga diukur dengan menggunakan instrumen work-family conflict milik Carlson et al. (2000) yang telah diadaptasi oleh Artiawati (2012) dan telah teruji sebagai alat ukur yang valid dan reliabel. Instrumen ini sendiri berjumlah 12 butir yang mewakili 4 dimensi yakni WIF-Time, WIF-Strain, FIWTime, FIW-Strain. Adapun hasil pengolahan data dari 117 responden menghasilkan alpha cronbach dari instrumen gaya kepemimpinan transformasional dan konflik kerja-keluarga sebesar 0,919 dan 0,934 dengan rentang koefisien korelasi antar item sebesar 0,314-0,801 dan 0,631-0,786. Pengujian hipotesis pada penelitian ini dilakukan dengan menggunakan aplikasi SPSS 16.00 dan uji non-paramaterik Spearman karena asumsi linearitas tidak terpenuhi.

\section{HASIL DAN PEMBAHASAN}

Hasil uji hipotesis menunjukkan besaran signifikansi yang lebih dari 0,05 ( $r=-0,093$, Sig. $=0,317)$ sehingga dapat disimpulkan bahwa tidak ada hubungan langsung yang signifikan antara gaya kepemimpinan transformasional atasan dan konflik kerja-keluarga karyawan. Adanya hasil yang demikian memunculkan asumsi bahwa terdapat aspek lainnya yang lebih berperan secara signifikan dalam menurunkan tingkat konflik kerja-keluarga karyawan mengingat bahwa penelitian ini dilakukan di Indonesia yang kental dengan budaya kolektivis dalam masyarakatnya, yakni aspek dukungan keluarga besar. Asumsi tersebut didasarkan pada hasil penelitian milik Artiawati \& Astutik yang mengungkapkan bahwa terdapat hubungan yang signifikan antara dukungan keluarga besar dengan kemampuan diri individu dalam mengatasi konflik kerja-keluarganya (Artiawati \& Astutik, 2017). 
Pengujian lebih lanjut kemudian dilakukan dan didapatkan hasil yang menunjukkan bahwa terdapat hubungan spesifik antara gaya kepemimpinan transformasional dengan salah satu aspek dari variabel konflik kerja-keluarga, yakni family interference work-strain (FIW-Strain) seperti yang nampak pada Tabel 5 di bawah ini. Family interference work-strain merupakan sebuah bentuk ketidakseimbangan peran hingga menimbulkan konflik kerjakeluarga dan terjadi karena peran individu di kehidupan rumah tangganya hingga mengganggu keberlangsungan peran dalam kehidupan pekerjaannya (Greenhaus \& Beutell, 1985).

Tabel 5. Uji Korelasi Gaya Kepemimpinan Transformasional dan Dimensi Konflik Kerja-Keluarga

\begin{tabular}{llcc}
\hline \multicolumn{1}{c}{ Variabel } & \multicolumn{2}{c}{ Spearman's rho } & Hubungan \\
\hline TL-WIF Time & $\mathbf{r}$ & Sig. & Tidak Ada Hubungan \\
TL-WIF Strain & -.010 & .914 & Tidak Ada Hubungan \\
TL- FIW Time & -.070 & .453 & Tidak Ada Hubungan \\
TL-FIW Strain & -.063 & .503 & Ada Hubungan \\
\hline
\end{tabular}

$* * \mathrm{p}<.01$

Pengujian lebih lanjut dilakukan untuk melihat hubungan antara family interference work-strain dengan ketujuh aspek dari gaya kepemimpinan transformasional dan diperoleh hasil bahwa 5 dari 7 dimensi gaya kepemimpinan transformasional yang meliputi dimensi vision, staff development, empowerment, innovative thinking, dan lead by example ternyata memiliki hubungan dengan family interference work-strain (FIW-Strain) yang dipaparkan lebih jelas pada tabel 6 berikut ini.

Tabel 6. Uji Korelasi Dimensi Gaya Kepemimpinan Transformasional dan Family Interference Work-Strain

\begin{tabular}{llll}
\hline \multirow{2}{*}{ Variabel } & \multicolumn{2}{c}{ Spearman's rho } & Hubungan \\
\hline TL Lead by Example - & r & Sig. & Ada Hubungan \\
FIW Strain & $-.254^{* *}$ & .006 & Ada Hubungan \\
TL Vision - & $-.255^{* *}$ & .006 & Ada Hubungan \\
FIW Strain & $-.220^{*}$ & .017 & Ada Hubungan \\
TL Staff Development -FIW Strain & $-.250^{* *}$ & .006 & Ada Hubungan \\
TL Empowerment - FIW Strain & $-.202^{*}$ & .029 & Tidak Ada Hubungan \\
TL Innovative Thinking- & -.175 & .060 & Tidak Ada Hubungan \\
FIW Strain & -.173 & .062 & \\
TL Supportive Leadership - & & & \\
FIW Strain & TL Charisma - & & \\
FIW Strain &
\end{tabular}

$* \mathrm{p}<.05, * *<.01$

Penjelasan terkait hasil korelasi antar aspek dari kedua variabel dapat dikaji dari konsep dasar konflik kerjakeluarga yakni terkait hubungan antar aspek konflik kerja-keluarga yang bersifat bidirectional interdependensi (Frone, 2003; Greenhaus, 2008). Hubungan interdependensi antar aspek konflik kerja-keluarga merujuk pada hubungan yang saling berkaitan dan berkesinambungan antara kehidupan keluarga dan pekerjaan seorang individu yang mengakibatkan terganggunya peran individu di salah satu ranah ketika individu tersebut memiliki permasalahan di ranah lainnya. Penelitian juga telah membuktikan bahwa terdapat hubungan timbal balik positif yang kuat antara kehidupan pekerjaan dan rumah tangga, yang berarti bahwa apabila seorang individu memiliki masalah berkaitan dengan tanggung jawab di tempat kerjanya dan mulai mengganggu kehidupan rumah tangganya, kehidupan rumah tangga yang terganggu itu akan balik mengganggu kehidupan pekerjaan individu tersebut (Frone et al., 1992). Oleh karena itu, adanya hubungan yang negatif antara gaya kepemimpinan transformasional dan FIW tidak dapat dilepaskan dari kaitannya dengan WIF. Dengan kata lain, semakin transformasional seorang atasan, maka semakin rendah pula konflik kehidupan keluarga yang berpotensi untuk mengganggu kehidupan pekerjaan karyawan. Namun, rendahnya konflik kehidupan keluarga yang berpotensi mengganggu kehidupan pekerjaan karyawan tersebut tidak dapat serta-merta dipisahkan dari bagaimana kehidupan pekerjaan yang dialami oleh karyawan tersebut mengingat hubungan interdependensi antara keduanya.

Hal lainnya yang patut untuk dicermati adalah bahwa bagaimana seorang atasan pun tidak bisa luput dari permasalahan terkait konflik kerja keluarga. Penelitian yang dilakukan oleh Ten Brummelhuis, Haar, dan Roche (2014) menyebutkan bahwa kehidupan rumah tangga para atasan ternyata dapat memengaruhi bagaimana performa atasan pada saat bekerja. Semakin rendah tingkat konflik rumah tangga yang dialami oleh para atasan, semakin para 
atasan dapat meningkatkan fungsi perannya di kehidupan pekerjaannya, termasuk dalam mememotivasi para karyawannya (Ten Brummelhuis et al., 2014). Hal tersebut akhirnya dapat meningkatkan well-being yang dimiliki oleh para karyawan. Selain itu, Ten Brummelhuis et al. (2014) juga menguji bagaimana well-being yang dimiliki oleh atasan dapat memengaruhi well-being yang dimiliki oleh para karyawannya dengan menggunakan dua metode mekanisme crossover yakni affective crossover (emosi yang ditampakkan atasan kepada bawahan) dan behavioral crossover (bentuk dukungan yang diberikan atasan kepada bawahan). Hasil menunjukkan bahwa affective crossover lebih cepat untuk diadaptasi oleh para karyawan dengan kata lain emosi yang ditampakkan oleh atasan lebih cepat menular pada karyawan dibandingkan behavioral crossover. Hal tersebut dikarenakan adanya suatu kondisi yang disebut sebagai emotional contagion.

Neumann dan Strack mengungkapkan bahwa emotional contagion merupakan suatu mekanisme yang menghasilkan kondisi emosi yang sejenis dengan kondisi emosi orang yang diobservasi (Neumann \& Strack, 2000; Ten Brummelhuis et al., 2014). Begitu pula dengan aspek perilaku yang ditunjukkan oleh atasan, para karyawan pun yang setiap hari harus bertemu dan berurusan dengan para atasan, secara tidak langsung akan membentuk dan meniru bagaimana pola perilaku atasan yang menjadi significant other dan role model bagi mereka. Hal tersebut mengakibatkan pola perilaku dan emosi yang dimiliki oleh para karyawan dengan meniru atasannya akan ditampilkannya dalam kehidupan sehari-harinya, termasuk dalam kehidupan rumah tangganya. Dengan kata lain, peran atasan yang transformasional sebagai sosok panutan atau role model benar terasa bagi para karyawannya. Hal tersebut mengindikasikan bahwa apabila emosi dan perilaku atasan yang ditunjukkan kepada karyawannya merupakan emosi dan perilaku yang positif, emosi dan perilaku tersebut akan diadaptasi pula oleh para karyawan dalam kehidupan rumah tangganya, dengan demikian hal tersebut dapat menurunkan tingkat konflik kehidupan rumah tangga karyawannya agar tidak sampai tumpang-tindih dengan kehidupan pekerjaan. Adanya peniruan emosi dan perilaku atasan dengan menjadikan atasan sebagai role model berkesinambungan dengan salah satu aspek dari transformational leadership yakni lead by example (Carless et al., 2000) yang juga menjadi salah satu aspek dari gaya kepemimpinan transformasional yang berkorelasi dengan FIW-Strain.

Selain aspek lead by example yang telah dijelaskan pada paragraf sebelumnya, terdapat pula aspek lain dari gaya kepemimpinan transformasional yang berkorelasi dengan FIW-Strain yakni vision. Aspek vision berkaitan dengan bagaimana pemimpin yang transformasional akan mengemukakan secara berulang-ulang tujuan dari perusahaan atau divisi mereka sehingga secara tidak langsung pemimpin tersebut menanamkan nilai-nilai yang dapat memotivasi karyawan mereka sehingga karyawan tersebut dapat bekerja selaras dengan nilai dan tujuan tersebut (Carless, Wearing, \& Mann, 2000). Adanya penyampaian tujuan hingga akhirnya menanamkan nilai yang dapat memotivasi karyawan tersebut dapat membantu karyawan untuk bisa mengenali potensi dan tanggung jawab dari peran yang memang dimilikinya. Hal tersebut juga dapat membantu mengurangi ambiguitas peran yang dapat tercipta sehingga dampak yang dimunculkan yakni akhirnya konflik kerja yang dimilikinya berkurang (Sana \& Aslam, 2018). Adanya konflik kerja yang berkurang dapat membawa pengaruh terhadap konflik kehidupan rumah tangganya yang juga dapat mengalami penurunan karena adanya hubungan interdependensi antara kedua jenis konflik tersebut (Frone, 2003; Greenhaus, 2008).

Aspek lainnya yakni staff development juga berhubungan dengan FIW-Strain karena dari aspek ini seorang pemimpin yang transformasional akan berusaha mengenali kebutuhan dan kemampuan dari satu-persatu karyawannya agar dapat mendorong perkembangan mereka sehingga para karyawan akan merasa percaya diri untuk bisa memberikan performa terbaik mereka (Carless, Wearing, \& Mann, 2000). Adanya usaha untuk mengenali kebutuhan dari masing-masing karyawannya menunjukkan bahwa pemimpin tersebut benar-benar menunjukkan rasa peduli dan empati terhadap hal yang mengganggu karyawan tersebut untuk bisa menunjukkan performa terbaiknya. Hal ini mengindikasikan bahwa atasan juga akan menunjukkan kepedulian terhadap masalah rumah tangga karyawannya yang sampai dapat mengganggu pekerjaan karyawan tersebut. Sebagai contoh, seorang karyawan mendapatkan kabar bahwa anaknya sedang sakit hingga akhirnya ia tidak mampu konsentrasi dalam bekerja, maka seorang pemimpin yang transformasional akan dapat mengenali bahwa karyawan tersebut sedang dalam masalah dan akan memberikan izin bagi karyawan itu untuk mengantarkan anaknya ke dokter karena hanya dengan cara itulah karyawan tersebut dapat merasa lebih tenang dan bisa konsentrasi kembali dalam bekerja. Adanya bentuk kepedulian dari atasan kepada para karyawannya mengindikasikan adanya bentuk dukungan yang diberikan atasan pada karyawannya atau yang dikenal sebagai supervisor support. Supervisor support mengacu pada bagaimana seorang atasan menghargai kontribusi karyawannya serta peduli terhadap well-being dari para karyawannya (Eisenberger et al., 1986; Mohamed \& Ali, 2016). Adanya pemberian supervisor support ternyata berdampak pada tingkat konflik yang dialami oleh para karyawan, khususnya konflik keluarga-pekerjaan (family-work conflict). Supervisor support ternyata menjadi prediktor yang signifikan berpengaruh terhadap tinggi rendahnya family-work conflict para karyawan (Frye \& Breaugh, 2004). Penemuan dari penelitian lain juga menyebutkan hal yang sama dimana dukungan dari atasan juga dapat memengaruhi kehidupan keluarga seorang karyawan dan dapat mengurangi konflik rumah tangga-pekerjaan (family-work conflict) dari karyawan tersebut (Karatepe \& Uludag, 2008).

Aspek berikutnya yakni aspek empowerment yang mana tipe pemimpin ini mampu untuk mengajak serta bawahannya dalam pembuatan keputusan, menghendaki adanya pemberian otonomi kerja, serta membuat para 
bawahannya penuh akan rasa percaya, toleransi, serta saling terbuka (Carless, Wearing, \& Mann, 2000). Aspek ini berhubungan dengan FIW-Strain secara negatif karena dengan adanya pemberian otonomi kerja, karyawan tersebut akan merasa lebih fleksibel dalam mengatur dirinya sendiri. Hal yang sama juga akan dilakukannya pada kehidupan rumah tangganya dimana para karyawan juga dapat memiliki otonomi dalam mengatur kehidupan rumah tangganya sehingga tidak akan terjadi tumpang-tindih antara kehidupan pekerjaan dengan kehidupan rumah tangga (Hammond et al., 2015). Selain itu, aspek ini juga menghendaki adanya rasa saling terbuka, dimana atasan juga dapat menjadi sosok teman bagi para karyawannya. Dengan demikian, para karyawan juga dapat terbuka pada atasannya tidak hanya mengenai masalah pekerjaan tetapi juga terkait masalah rumah tangganya. Hal ini tentunya dapat membantu mengurangi konflik rumah tangga karena karyawan merasa memiliki teman untuk mengeluarkan keluh kesah yang dimilikinya.

Aspek lainnya yang berkorelasi dengan FIW-Strain adalah aspek innovative thinking yang mana pemimpin transformasional merupakan tipe pemimpin yang berani mengambil risiko dan juga dapat mendorong para karyawannya untuk mampu memikirkan cara-cara baru dalam meraih tujuan (Carless, Wearing, \& Mann, 2000). Selain itu, pemimpin dengan aspek ini adalah tipe pemimpin yang dapat memberikan toleransi terhadap kesalahan karena menganggap kesalahan merupakan hal yang lumrah dan sebagai sebuah proses untuk belajar (Carless, Wearing, \& Mann, 2000). Karena adanya pemimpin yang demikian, karyawan akan merasa terdorong dan berani mengambil tindakan serta tanggung jawab. Karyawan juga akan terbiasa untuk berpikir secara kreatif. Adanya stimulasi untuk dapat berpikir dan bertindak secara kreatif berkaitan dengan salah satu aspek kepribadian yakni openness (Judge et al., 1999). Kebiasaan untuk berpikir secara kreatif dalam menghadapi berbagai permasalahan dan tugas dalam pekerjaan dapat berdampak pula bagi kehidupan rumah tangga karyawan tersebut, dimana ia dapat memikirkan cara-cara yang lebih kreatif dalam mengatasi tanggung jawab dan persoalan rumah tangganya. Hasil penelitian menyebutkan bahwa semakin tinggi kepribadian openness seseorang, maka semakin banyak pula ide-ide kreatif yang dihasilkan. Semakin banyak ide kreatif yang dihasilkan oleh seseorang, maka mereka akan semakin mampu pula untuk menemukan solusi kreatif untuk mengatasi konflik mereka (Priyadharshini \& Wesley, 2014). Selain itu, pemberian rasa toleran yang dimiliki oleh atasan terhadap karyawan dapat dipraktikkan pula oleh para karyawan di kehidupan rumah tangganya sehingga dengan adanya rasa saling toleransi yang terbentuk dengan pasangan, tingkat konflik rumah tangga akan dapat diminimalisir.

Pemaparan mengenai dinamika hasil penelitian tersebut rupanya sejalan dengan hasil asesmen data awal penelitian yakni dengan metode wawancara yang telah dilakukan kepada 3 orang representatif karyawan perusahaan manufaktur sepeda di Gresik. Mereka merasa minim mengalami konflik dalam lingkungan keluarga dan pekerjaan karena tanggung jawab yang harus mereka jalankan diberikan secara jelas dan tidak ada ambiguitas sebagai imbas karena atasan mereka yang jelas dalam memberikan arahan dan tujuan yang hendak diraih. Selain itu, adanya pemberian otonomi kerja dan kebebasan dalam menyelesaikan tanggung jawab juga sangat membantu para karyawan karena mereka merasa lebih fleksibel dalam menyesuaikan waktu untuk mengurus kepentingan keluarga dan pekerjaannya sehingga mereka merasa adanya pembagian waktu yang lebih jelas antara perannya di keluarga dan pekerjaan. Hal yang tidak kalah penting berdampak terhadap minimnya konflik yang mereka alami yakni karena atasan mereka yang peduli terhadap persoalan dan kebutuhan masing-masing karyawan serta memahami dan menoleransi mereka apabila terpaksa harus memprioritaskan keluarga secara mendadak.

Selain pemaparan mengenai peran atasan dalam mereduksi tingkat konflik FIW-Strain, ternyata penelitian ini juga menghasilkan satu penemuan lain yakni adanya asosiasi antara jenis kelamin atasan dengan tingkat konflik kerjakeluarga karyawannya seperti yang nampak pada tabel 7. Hal ini sejalan dengan asumsi yang dikemukakan oleh Bass bahwa jenis kelamin juga memengaruhi transformasional atau tidaknya seorang pemimpin (Bass, 1999).

Tabel 7. Hasil Tabulasi Silang Konflik Kerja-Keluarga dan Data Demografis

\begin{tabular}{ccc}
\hline Tabulasi Silang & Sig. & Status \\
Konflik Kerja-Keluarga & .822 & Tidak ada asosiasi \\
Jenis Kelamin & .262 & Tidak ada asosiasi \\
Usia & .588 & Tidak ada asosiasi \\
Latar Belakang Pendidikan & .314 & Tidak ada asosiasi \\
Lama Bekerja & .137 & Tidak ada asosiasi \\
Pasangan Bekerja & .195 & Tidak ada asosiasi \\
Pekerjaan Pasangan & .835 & Tidak ada asosiasi \\
Lama Pernikahan & .753 & Tidak ada asosiasi \\
Jumlah Anak & $\mathbf{. 0 0 1}$ & Ada asosiasi \\
\hline
\end{tabular}


Tabel 8. Hasil Tabulasi Silang Jenis Kelamin Atasan dan Konflik Kerja-Keluarga

\begin{tabular}{|c|c|c|c|c|c|c|c|c|c|c|c|c|}
\hline \multirow{3}{*}{ Jenis Kelamin Atasan } & \multicolumn{12}{|c|}{ Konflik Kerja-Keluarga } \\
\hline & \multicolumn{2}{|c|}{ SR } & \multicolumn{2}{|c|}{$\mathbf{R}$} & \multicolumn{2}{|c|}{$\mathbf{S}$} & \multicolumn{2}{|c|}{$\mathbf{T}$} & \multicolumn{2}{|c|}{ ST } & \multicolumn{2}{|c|}{ Total } \\
\hline & f & $\%$ & f & $\%$ & f & $\%$ & f & $\%$ & f & $\%$ & f & $\%$ \\
\hline Pria & 12 & 13,8 & 42 & $\begin{array}{c}48,3 \\
\%\end{array}$ & 21 & $\begin{array}{c}24,1 \\
\%\end{array}$ & 12 & $\begin{array}{c}13,8 \\
\%\end{array}$ & 0 & $\begin{array}{c}0 \\
\%\end{array}$ & 87 & $\begin{array}{c}100 \\
\%\end{array}$ \\
\hline Wanita & 7 & $\begin{array}{c}31,8 \\
\%\end{array}$ & 9 & $\begin{array}{c}40,9 \\
\%\end{array}$ & 4 & $\begin{array}{c}18,2 \\
\%\end{array}$ & 1 & $\begin{array}{c}4,5 \\
\%\end{array}$ & 1 & $\begin{array}{c}4,5 \\
\%\end{array}$ & 22 & $\begin{array}{c}100 \\
\%\end{array}$ \\
\hline
\end{tabular}

Jika dilihat dari arah distribusi tabulasi silang pada tabel 8 antara jenis kelamin atasan dengan konflik kerja-keluarga, dapat dilihat bahwa karyawan yang memiliki atasan berjenis kelamin pria cenderung memiliki tingkat konflik kerjakeluarga dari rendah ke sedang. Sementara itu, karyawan yang memiliki atasan berjenis kelamin wanita justru memiliki tingkat konflik kerja-keluarga yang cenderung rendah ke sangat rendah. Adanya perbedaan yang demikian menjadi hal yang menarik untuk dicermati bahwa jenis kelamin ternyata dapat berasosiasi terhadap transformasional atau tidaknya seorang atasan, yang untuk selanjutnya hal tersebut juga dapat berdampak terhadap tinggi rendahnya konflik kerja-keluarga yang dialami oleh karyawan karena atasan juga merupakan salah satu prediktor atau determinan yang dapat memengaruhi konflik kerja-keluarga karyawan (Kailasapathy \& Jayakody, 2018). Hasil dari penelitian ini menunjukkan bahwa seorang atasan wanita menjadi sosok yang lebih transformasional bagi karyawannya karena mereka lebih memiliki empati terhadap karyawannya sehingga lebih memudahkan atasan wanita dalam memberikan dukungan dan bantuan terhadap karyawannya, termasuk dalam memahami permasalahan dalam lingkup keluarga dan pekerjaan (Vongas \& Al Hajj, 2015). Kondisi tersebut semakin didukung juga dengan adanya karakteristik dari atasan wanita yang cenderunglebih engage dalam setiap perilakunya untuk menampilkan kualitas terbaik dari kepemimpinan (Aamodt, 2010; Eagly et al., 2003).

\section{SIMPULAN}

Penelitian ini memberikan pemahaman terkait faktor-faktor gaya kepemimpinan yang secara spesifik dapat berkaitan dengan tingkat konflik kerja-keluarga karyawan. Vision, staff development, empowerment, innovative thinking, dan lead by example menjadi faktor-faktor gaya kepemimpinan transformasional yang dapat membantu mereduksi tingkat konflik kerja-keluarga para karyawan, khususnya family interference work-strain. Selain itu, adanya penemuan lain yakni terkait adanya indikasi pengaruh dari jenis kelamin atasan terhadap tinggi rendahnya tingkat konflik kerja-keluarga karyawan menjadi hal yang menarik untuk diteliti lebih lanjut. Pada penelitian ini, atasan berjenis kelamin perempuan cenderung lebih transformasional dibandingkan atasan berjenis kelamin laki-laki, sehingga karyawan cenderung memiliki tingkat konflik kerja-keluarga yang lebih rendah apabila dipimpin oleh atasan berjenis kelamin perempuan dibandingkan yang dipimpin oleh atasan berjenis kelamin laki-laki.

Sehubungan dengan adanya penemuan tersebut, maka peneliti mengharapkan adanya penelitian lebih lanjut dan spesifik terhadap peran jenis kelamin atasan terhadap tingkat konflik kerja-keluarga karyawan. Kemudian, peneliti mengharapkan agar penelitian berikutnya juga melakukan pengukuran terhadap tingkat konflik kerja-keluarga dari para atasan agar dapat dilihat apakah memang terjadi proses modeling dari karyawan terhadap atasannya yang akhirnya berpengaruh pula terhadap konflik kerja-keluarga dari para karyawannya. Selain itu, penelitian berikutnya diharapkan dapat memperhitungkan rasio jenis kelamin responden agar tidak berbanding terlalu jauh dan menambahkan pertanyaan pada angket terbuka untuk menggali perilaku-perilaku atasan yang sekiranya menurut para karyawan dapat membantu mereka dalam menurunkan konflik kerja-keluarga yang dimilikinya serta menyamakan level jabatan dari para partisipan agar data yang diperoleh lebih homogen. 


\section{DAFTAR PUSTAKA}

Aamodt, M. G. (2010). Industrial/organizational psychology: an applied approach (6th ed.). Wadsworth Cengage Learning.

Amiruddin, A., Pagalung, G., Kartini, \& Arifuddin. (2019). Mediating effect of work stress on the influence of time pressure, work-family conflict and role ambiguity on audit quality reduction behavior. International Journal of Law and Management, 61(2), 434-454.

Amstad, F. T., Meier, L. L., Fasel, U., Elfering, A., \& Semmer, N. K. (2011). A meta-analysis of work-family conflict and various outcomes with a special emphasis on cross-domain versus matching-domain relations. Journal of Occupational Health Psychology, 16(2), 151-169.

Arnold, K. A., Turner, N., Barling, J., Kelloway, E. K., \& Mckee, M. C. (2007). Transformational leadership and psychological well-being : the mediating role of meaningful work. Journal of Occupational Health Psychology, 12(3), 193-203.

Artiawati, \& Astutik, N. P. (2017). Hubungan keyakinan diri mengelola konflik kerja-keluarga, dukungan atasan, dan dukungan keluarga dengan pengayaan kerja-keluarga. Journal of Psychological Science and Profession, 1(1), $1-8$.

Bass, B. M. (1997). Does the Transactional - Transformational Leadership Paradigm Transcend Organizational and National Boundaries? American Psychologist, 52(2), 130-139.

Bass, B. M. (1999). Two decades of research and development in transformational leadership. European Journal of Work and Organizational Psychology, 8(1), 9-32.

Bass, B. M., \& Avolio, B. J. (1990). Developing transformational leadership: 1992 and beyond. Journal of European Industrial Training, 14(5), 21-27.

BPS-RI. (2019). Keadaan angkatan kerja di Indonesia.

Carless, S. A., Wearing, A. J., \& Mann, L. (2000). A short measure of transformational leadership. Journal of Business and Psychology, 14(3), 389-405.

Carlson, D. S., Kacmar, K. M., \& Williams, L. J. (2000). Construction and initial validation of a multidimensional measure of work - family conflict. Journal of Vocational Behavior, 56, 249-276.

Eagly, A. H., Johannesen-schmidt, M. C., \& van Engen, M. L. (2003). Transformational , transactional , and laissezfaire leadership styles : a meta-analysis comparing women and men. Psychological Bulletin, 129(4), 569-591.

Eisenberger, R., Huntington, R., Hutchison, S., \& Sowa, D. (1986). Perceived organizational support. Journal Of Applied Psychology, 71(3), 500-507.

Elloy, D. F., \& Smith, C. R. (2003). Patterns of stress, work-family conflict, role Conflict, role ambiguity and overload among dual-career and single-career couples : an Australian study. Cross Cultural Management: An International Journal, 10(1), 55-66.

Frone, M. R. (2003). Work-Family Balance. In J. . Quick \& L. . Tetrick (Eds.), Handbook of occupational health psychology (pp. 143-162). American Psychological Association.

Frone, M. R., Russell, M., \& Cooper, M. L. (1992). Antecedents and outcomes of work-family conflict: testing a model of the work family interface. Journal Of Applied Psychology, 77(1), 65-78.

Frye, N. K., \& Breaugh, J. A. (2004). Family-friendly policies, supervisor support, work-family conflict, familywork conflict, and satisfaction : a test of a conceptual model. Journal of Business, 19(2), 197-220.

Gillet, N., Fouquereau, E., Huyghebaert, T., \& Vandenberghe, C. (2016). Transformational leadership, work-family conflict and enrichment, and commitment. Travail Humain, 79(4), 339-362.

Goh, J., Pfeffer, J., \& Zenios, S. A. (2015). The relationship between workplace stressors and mortality and health costs in the United State. Management Science, 62, 1-21.

Greenhaus, J. H. (2008). Innovations in the study of the work - family interface : introduction to the special section. Journal of Occupational and Organizational Psychology, 81, 343-348.

Greenhaus, J. H., \& Beutell, N. J. (1985). Sources of conflict between work and family roles. The Academy of Management Review, 10(1), 76-88.

Hammond, M., Cleveland, J. N., O’Neill, J. W., Stawski, R. S., \& Tate, A. J. (2015). Mediators of transformational leadership and the work-family relationship. Journal of Managerial Psychology, 30(4), 454-469.

Judge, T. A., Higgins, C. A., Thoresen, C. J., \& Barrick, M. R. (1999). The big five personality traits, general mental ability, and career success across the life span. Personnel Psychology, 52, 621-652.

Kailasapathy, P., \& Jayakody, J. A. S. K. (2018). Does leadership matter? leadership styles, family supportive supervisor behaviour and work interference with family conflict. International Journal of Human Resource Management, 29(21), 3033-3067.

Karatepe, O. M., \& Uludag, O. (2008). Supervisor support, work-family conflict, and satisfaction outcomes: an empirical study in the hotel industry. Journal of Human Resources in Hospitality and Tourism, 7(2), 115-134.

KEMENPPA. (2016). Statistik gender tematik-potret ketimpangan gender dalam ekonomi.

LaRocco, J. M., House, J. S., \& French, J. R. P. (1980). Social support, occupational stress, and health. Journal of 
Health and Social Behavior, 21(3), 202-218.

Li, Y., Sawhney, R., \& Tortorella, G. L. (2019). Empirical analysis of factors impacting turnover intention among manufacturing workers. International Journal of Business and Management, 14(4), 1-18.

Liao, E. Y., Lau, V. P., Hui, R. T., \& Kong, K. H. (2019). A resource-based perspective on work - family conflict: meta-analytical findings. Career Development International, 24(1), 37-73.

Magnini, V. P. (2009). Understanding and reducing work-family conflict in the hospitality industry. Journal of Human Resources in Hospitality and Tourism, 8(2), 119-136.

Meyer, J. P., \& Tett, R. P. (1993). Job satisfaction, organizational commitment, turnover intention, and turnover: path analyses based on meta-analytical findings. Personnel Psychology, 46(2), 259-293.

Mohamed, S. A., \& Ali, M. (2016). The importance of supervisor support for employees' affective commitment: an analysis of job satisfaction. International Journal of Scientific and Research Publications, 6(2), 435-439.

Neumann, R., \& Strack, F. (2000).' Mood contagion ": the automatic transfer of mood between persons. Journal of Personality and Social Psychology, 79(2), 211-223.

Pan, S., \& Yeh, Y.-J. (2019). The crossover effect of work - family conflict among hotel employees. International Journal of Contemporary Hospitality Management, 31(2), 812-829.

Perry, S. J., \& Penney, L. (2010). The downside of goal-focused leadership : the role in personality in subordinate exhaustion. Journal Of Applied Psychology, 95(6), 1145-1153.

Priyadharshini, R. A., \& Wesley, R. J. (2014). Personality as a determinant of work-family conflict. Journal of Industrial Engineering and Management, 7(5), 1037-1060.

Reimann, M., Marx, C. K., \& Diewald, M. (2019). Work-to-family and family-to-work conflicts among employed single parents in Germany. Equality, Diversity, and Inclusion: An International Journal, 39(5), 513-531.

Sana, F., \& Aslam, N. (2018). Effect of role ambiguity and role conflict in predicting work-family conflict among teachers. Pakistan Journal of Psychological Research, 33(2), 349-365.

Sherman, D. J. (1999). Methodology in geomorphology: traditions and hypocrisy. Annals of the Association of American Geographers, 89(4), 687-696.

Spross, J. (2018, April 27). Your job is killing you. The Week. Retrieved from http://theweek.com/articles/768459/jobkilling

Ten Brummelhuis, L. L., Haar, J. M., \& Roche, M. (2014). Does family life help to be a better leader? A closer look at crossover processes from leaders to followers. Personnel Psychology, 67(4), 917-949.

Tziner, A., \& Sharoni, G. (2014). Organizational citizenship behavior, organizational justice, job stress, and workfamily conflict: examination of their interrelationships with respondents from a non-western culture. Journal of Work and Organizational Psychology, 30(1), 35-42.

Vongas, J. G., \& Al Hajj, R. (2015). The evolution of empathy and women's precarious leadership appointments. Frontiers in Psychology, 6, 1-14.

Yeow, J. A., Tan, K., \& Chin, T. S. (2012). A review on ergonomic factors that lead to stress in manufacturing industry. International Conference of Management, Economics, and Finance. 